\title{
Proposed Models of Functional Heterogeneity in Cancer and the Effects of Microenvironmental Factors on Cancer Stem Cells: A Literature Review
}

\author{
Neetu N. Rambharack, BSc Student [1], Ying R. Guo, BSc Student [2] \\ [1] Faculty of Science, McMaster University, Hamilton, Ontario, Canada L8S 4L9 \\ [2] Faculty of Science, University of Waterloo, Waterloo, Ontario, Canada N2L 3G1 \\ *Corresponding Author: rambharn@mcmaster.ca
}

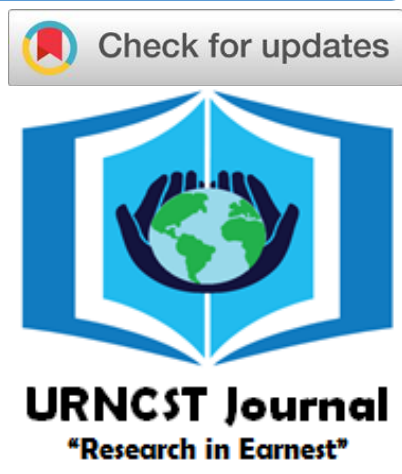

\begin{abstract}
Introduction: Functional heterogeneity in cancer may result in the metastasis of various types of tumour cells throughout the body. Attempting to explain functional heterogeneity in cancer cells has given rise to two models. The Cancer Stem Cell model proposes that a subset of tumour cells self-replicate and that heterogeneity is a progeny of various cancer stem cells (CSCs). The Clonal Evolution Model proposes heterogeneity as a product of mutations across tumour cells that accumulate and metastasize linearly or branching.

Methods: Research was conducted through open-access journals and information was compiled surrounding CSC models using the Google Scholar and McMaster Library database search engines. Inclusions were sources that detailed the relationship between both models of functional heterogeneity and microenvironments and treatments. Literature that did not center around tumour microenvironments was not included in this literature review.

Results: The two main models of tumour proliferation were explored and related to hypoxic tumour microenvironments. Various markers, etiologic agents and toxins were identified that contribute to tumour progression. Cell signalling and pathways that contribute to major cellular functions were identified, along with possible disruptions and epigenetic changes that lead to tumour and CSC proliferation.

Discussion: This study reveals that the tumour microenvironment plays a large role in the proliferation of CSCs. Although the therapies targeting microenvironments are in early stages of development, focusing on these CSC targeted- therapies may lead to better treatments for cancer or more effective combination therapies. Strengths of the paper include the compilation of major contributing areas to CSC proliferation, whereas limitations encompass the high variability of tumour cells that are not all covered in this review.

Conclusion: While no definitively eradicating treatment for CSCs currently exist, the recent developments in cancer research indicate promising new techniques for its management.

Implications: By further studying malignant CSCs, highly effective cancer treatments may result, leading to the advancement of CSC recognition and combination therapy.
\end{abstract}

Keywords: cancer; cancer stem cells; clonal evolution; functional heterogeneity; microenvironments

\section{Introduction}

Since the first documented case of cancer in Egyptian papyri from 2700 years ago, extensive research has been done to advance the overall understanding of this disease [1]. Due to its variable and spontaneous nature, treatments must be equally as variable and determined on a case-by-case basis. Investigating the root causes of cancer in a patient can provide more insight into targeting and preventing cancer at the source.

Cancer stem cells (CSCs) are a minor population of tumorigenic cancer cells found in malignant tumours that may also drive metastasis [2]. Regarded as a stemming point for the heterogeneity observed in tumours, the understanding of CSC growth is mainly governed the clonal evolution model. This model proposes tumour heterogeneity as variability within CSCs and its non-tumorigenic progeny [3]. A subset of cancer cells are able to metastasize and produce genetic variation within one patient, increasing the difficulty of eradicating a malignant tumour without combination therapeutics [3].

Tumor heterogeneity involves the difference in genetic makeup between different cancer cells in a single tumor. Tumor heterogeneity can arise from various genetic or epigenetic changes that arise within a tumor population, that leads to an increase in genetic instability [3]. The level of functional heterogeneity varies between patients, increasing the difficulty of proposing treatment models specific to each case. The tumor microenvironment plays a crucial role in the 
UNDERGRADUATE RESEARCH IN NATURAL AND CLINICAL SCIENCE AND TECHNOLOGY (URNCST) JOURNAL Read more URNCST Journal articles and submit your own today at: https://www.urncst.com

proliferation and differentiation of CSCs [4]. Vascular niches, hypoxia, tumour-associated macrophages and CSCs make up a large portion of a tumor microenvironment that leads to increased metastasis [4]. Heterogeneity introduces varying challenges to tumour treatments which to date have been tackled by using combination therapies [5]. Although the breadth of knowledge surrounding cancer is fairly large, leveraging this information into effective treatments is an important next step.

This article summarises the clonal evolution model, that attempts to explain the proliferation of CSCs leading to heterogeneity within a tumor, and discusses potential areas to target that may result in a reduction of tumour growth. This article also outlines new technologies that aid in the identification and targeting of CSCs.

\section{Methods}

$\underline{\text { Research Question }}$

The research was conducted through open-access journals and information was compiled surrounding CSC models, functional heterogeneity and a centered around microenvironments. A general search through the McMaster University Library database was used. Information was filtered to include literature reviews that detailed both models of functional heterogeneity. Exclusions to this search included those that detailed chemotherapeutics.

\section{$\underline{\text { Search Strategies }}$}

The Google Scholar search engine was used to collect academic papers surrounding tumour microenvironments that detailed the relationship between both models of functional heterogeneity and microenvironments and treatments for CSC microenvironments. Literature that did not center around tumour microenvironments was not included in this literature review. Literature centering around hypoxia was chosen to be the focused example of microenvironment changes causing CSC growth.

The Google Scholar search engine was used to collect academic papers surrounding the clonal evolution model and microenvironments. Inclusions to this search involved academic papers that contained information about intrinsic and extrinsic microenvironments, the clonal evolution model as well as driving factors that have been identified to progress the cancers. Specific searches to fill gaps were made to finish areas that needed pieces of information to complete.

\section{Results}

The results of this study detail the effects of intrinsic and extrinsic microenvironments on the proliferation and heterogeneity of cancers, in accordance with the clonal evolution model and the cancer stem cell model.

Clonal Evolution Model and Tumor Heterogeneity

The clonal evolution model describes a series of subsequent tumorigenic mutations originating from an original cancerous stem cell [6]. Evolution of the genetic makeup of a tumor may occur through the expansion of driver genes and tumour suppressor genes [6]. Selective pressure mainly occurs in a branched pattern, leading to newly acquired mutations with each new generation of cells, however the time in which new mutations appear within the tumor varies [6]. Increased genomic instability with each successive generation may lead to selective advantages for certain tumour cell populations over longer periods of time. The pattern of branched expansion is thought to heavily contribute to tumour heterogeneity [6].

The model of clonal evolution proposes CSC proliferation with successive gene mutations with each new generation. Neo-Darwinism provides the basis of the clonal evolution model, suggesting that with each successive mutant generation comes the potential to develop selective advantages, although rare, in relation to survival within the microenvironment in which that colony thrives [7]. Thus, intrinsic microenvironments, consisting of the metabolic and genetic factors that contribute to their oncogenic activity may lead to the increased genetic instability that forms the clonal evolution model [8].

\section{CSC Signalling Pathways}

A study by Laconi (2007) found that DNA damage often occurs due to the oxygen reactive species that are generated from hypoxic conditions [8]. A hypoxic microenvironment reduces the efficacy of DNA repair mechanisms and may lead to gene amplification events [9]. The motility of tumorigenic cells was also shown to increase under hypoxic conditions, leading to the metastasis of an original colony faster than anticipated [10]. Understanding key mutations responsible for the successive mutations with each new cell division cycle is essential to predict metastasis and progression [7]. Over years of sequencing possible genes with suspected driver mutations, thousands have been found with many involving only a single nucleotide substitution [11]. Instead of targeting a single mutation, targeting pathways that induce mutation or lead to proliferation would be more effective when it comes to developing treatments [11].

There are six main signalling pathways involved in CSC proliferation, caused by the upregulation of key mutations in their pathway components. 1. The JAK/STAT pathway is heavily involved in maintaining CSC renewal, hematopoiesis and neurogenesis [12]. The overexpression of the NK, IFNGR, IL6, CSF2, and STAT1 genes led to upregulation of their respective signalling proteins found in breast cancer CSCs [12]. 2. The Hedgehog pathway is responsible for the resident CSC and progenitor cell populations of a tumor, which is normally responsible for organ development during embryogenesis [12]. Human gliomas were shown to overexpress the Gli1, SHH, and PATCHED1 genes from the Hedgehog pathway leading to an increase in proliferation, survival and self-renewal [12]. 3. The Wnt/ $\beta$-catenin pathway has been linked to CSC 
UNDERGRADUATE RESEARCH IN NATURAL AND CLINICAL SCIENCE AND TECHNOLOGY (URNCST) JOURNAL Read more URNCST Journal articles and submit your own today at: https://www.urncst.com

metastasis and maintenance of CSC stemming behaviour [12]. Key mutations have been identified to upregulate LEF1, cyclin D1, $\beta$-catenin, and TCF-4 signalling proteins in CSCs of breast cancer tumor cells, in comparison to non stem cells [12]. 4. The Notch pathway influences the specification and differentiation of stem cells during embryogenesis, and regulates various properties of tumor cells, however evidence of its use in CSCs is now starting to develop [12]. The signalling genes Notch1, Notch3, Jag1, Jag2, are upregulated in the Notch pathway, as found from pancreatic CSCs [12]. 5. The PI3K pathway is involved in progression of the cell cycle and cell growth cycle and activation of the PI3K/Akt/mTOR pathway leads to CSC radioresistance [13] 6 . The $\mathrm{NF}-\kappa \mathrm{B}$ pathway regulates bodily immune responses, cell proliferation, survival and differentiation; the connection to CSCs is fairly unclear [12]. Breast cancer cells have shown upregulation of the stemness factor LIN28 and the activated form of the downstream effector IKK $\beta$ in CSCs, in comparison to the non stem cancer cells.

\section{Epigenetic Changes in CSCs}

There are various epigenetic changes that may lead to increased genetic instability in CSCs. An increase in genetic instability has the potential to introduce new mutations into a tumor colony, with the rare possibility of being advantageous and allowing the colony to continue to thrive. The pathways mentioned previously are often heavily influenced by these epigenetic changes [14]. Three main epigenetic factors that can lead to increased genetic instability within CSCs are: 1. Increased DNA methylation that may contribute to increased oncogenic activity by inducing genetic instability [14]. DNA Methyltransferase (DNMT) inhibitors have been shown to decrease DNA methylation by targeting and reduce CSC proliferation and tumorigenic ability [15]. 2. Histone deacetylation modifications that may lead to the silencing of certain genes, in the case of CSCs, the silencing of tumor suppressor genes [15]. Using histone deacetylase (HDAC) inhibitors has shown to re-sensitize CSCs to chemotherapeutics, and differentiate out of their dormant state, to prevent tumor metastasis [15]. 3. Deregulation of chromatin remodelling that results in tumor progression which can be regulated by both DNMT and HDAC inhibitors [15]. The aim of DNMT and HDAC inhibitors is to resensitize CSCs with accumulated mutations to chemotherapeutics and halt tumor progression [15].

\section{Cancer Stem Cell Model and Microenvironments}

The complex interactions between CSCs and the niche microenvironment regulate and maintain CSC characteristics [16]. Extrinsic factors within the microenvironment can further support the cancer stem cell model and how a subset of CSCs are primed to metastasize. Extrinsic microenvironmental factors such as nutrient supply, blood supply and surrounding conditions such as $\mathrm{pH}$ and temperature may encourage cancer stem cell proliferation
[17]. Several extrinsic factors that result in the induction or proliferation of cancer stem cells are outlined below.

\section{Hypoxic Microenvironments}

Hypoxia is classified as a condition in which a region of the body does not receive sufficient oxygen [9]. Over time, this can result in cell death. However, when cells are exposed to hypoxic environments, hypoxia can cause DNA damage, which may result in the proliferation of cancerous stem cells [9]. Hypoxia induces the expression of stem cell markers such as NANOG, c-MYC and OTC4 and can upregulate stem cell markers which promote stem-like tumour cell phenotypes and enhance multi-drug resistance [10]. As well, research has suggested that epithelial-mesenchymal transition (EMT) initiation pushes cells to be more stem-like [10]. These phenotypes induced by the process of EMT can result in the proliferation of $\mathrm{CSCs}$ and resistance to traditional cancer treatments [10]. EMT plays a critical role in cell movement and organ formation in the adult human body and during embryogenesis [9]., Hypoxia can also affect the expression of certain genes involved in EMT, causing the metastasis of CSCs [9].

\section{Chronic Inflammation}

Chronic inflammation is recognized as an important factor that contributes to carcinogenesis in some indications [18]. Inflammation can be induced by a number of factors such as chronic infections, immunological factors, physical injury and chemical factors [19]. Together, chronic inflammation is estimated to account for the induction of almost $25 \%$ of human cancers [19]. Under inflammatory conditions, epithelial and inflammatory cells generate reactive oxygen species (ROS) and reactive nitrogen species (RNS) that are capable of causing damage to RNA, DNA, protein, and lipids [20]. ROS is known to induce the formation of oxidative DNA lesion products that are considered mutagenic [20].

The development of chronic inflammation has been associated with cytokines such as interleukin (IL) 1, IL-6, IL8 that are capable of affecting tumour growth through the regulation of CSCs. Interleukin-1, a cytokine produced during a response to tissue injury or infection. The production of IL-1 from tumour associated macrophages promotes features such as tumour growth and metastasis [21]. IL-6 also plays a role in immunoregulation but has recently been associated with chronic inflammatory states, hypertension, poor survival in cancer patients and increased risk of malignancy [21]. As well, IL-6 is a direct regulator of breast cancer stem cell self-renewal through mediation by the IL-6 receptor [21]. Within the tumor microenvironment, mesenchymal cells, macrophages and other immune cells secrete IL-8. in breast cancer, IL-6 and IL-8 activates Stat3 which further induces a tumorigenic microenvironment [19]. This results in the activation of NF-kB in inflammatory cells which secrete additional IL-6 and IL-8, completing the 
UNDERGRADUATE RESEARCH IN NATURAL AND CLINICAL SCIENCE AND TECHNOLOGY (URNCST) JOURNAL Read more URNCST Journal articles and submit your own today at: $\underline{\text { https://www.urncst.com }}$

positive feedback loop that stimulates CSC characteristics [19].

In recent years, EMT has been thoroughly investigated and its relationship to aggressive CSCs has been noted [22]. EMT plays a critical role in cell movement and organ formation in the adult human body and during embryogenesis [22]. In early embryogenesis, lineages of epithelial cells can give rise to a more mesenchymal phenotype [21]. This process is referred to as EMT or epithelial to mesenchymal transition. As a result of this transition, cells gain the ability to migrate and invade local tissues. The process of EMT is controlled by a number of microenvironmental factors and has recently been tied to the inflammatory process. The binding of signaling molecules such as IL-6, IL-8, TGF $\beta 1$ and HIF $1 \alpha$ to their respective receptors results in changes in downstream signalling molecules, many which overlap with pathways that regulate CSCs [21].

Hypoxia can also affect the expression of certain genes involved in EMT, causing the metastasis of CSCs [22]. Stem cell niches are often characterized by hypoxic environments as the low levels of oxygen minimize DNA damage caused by DNA oxidation. Hypoxia is classified as a condition in which a region of the body does not receive sufficient oxygen [22]. Over time, this can result in cell death. However, when cells are exposed to hypoxic environments, hypoxia can cause DNA damage, which may result in the proliferation of cancerous stem cells [22]. Hypoxia induces the expression of stem cell markers such as NANOG, c-MYC and OTC4 and can upregulate stem cell markers which promote stem-like tumour cell phenotypes and enhance multi-drug resistance [23] Hypoxia inducible factors are a group of transcriptional factors that are involved in the physiological response to oxygen concentration and can be induced by hypoxic microenvironments.

Cancer stem cells seem to exhibit an increased capability for DNA damage response when they express HIF 1 $\alpha$ [24]. The ability of malignant cells to survive under hypoxic environments is under the regulation of HIFs which are capable of activating CSC specific pathways such as Notch and Oct4 [24]. In addition to this, hypoxia has also been shown to regulate and increase the expression of CSC cell surface markers such as CD133, CD44, NANOG, cMYC and OCT4 and related genes such as SOX4 and SOX2 [22]. In glioma cells, the induction of HIF $1 \alpha$ in a hypoxic environment upregulates SOX2, promoting a stem-like tumor cell phenotype [22]. Similarly, in non-stem glioma cells, HIF $2 \alpha$ is induced in a hypoxic environment and leads to the induction of NANOG, c-YMC and OCT4. HIF $2 \alpha$ is solely responsible for the induction of CSC phenotypes in glioblastomas [22].

\section{Discussion}

In the clonal evolution model, mutations arise mainly in a branched pattern that often gives rise to new mutations in successive generations. Studying the clonal evolution model gives insight on how CSCs proliferate as a result of niche microenvironments.

Current cancer treatments focus heavily on chemotherapeutics, however, when used in combination therapies, are very detrimental to the patient. The patient endures high levels of toxicity, and it is imperative that research continues to find new methods to identify and treat these cancers. Targeted therapy provides a better alternative as the associated toxicity is limited.

Regulating the tumor microenvironment may result in new, effective cancer treatment therapies. These applications may be widely applied to numerous cancer types as many tumours have similar niche characteristics. Recognizing and inhibiting specific CSC markers can reduce the proliferation of cancerous cells. In the case of hypoxia, the binding of EZN-2698 to the mRNA of HIF-1 blocks its expression and has led to improved responses to cancer therapies [22]. While the inhibition of cancer stem cell markers alone is not an ideal treatment for cancer, when used to assist combination therapies, it has shown favourable results. These new developments can change the way combination therapies are administered making these highly toxic treatments more precise.

Additionally, with the amount of evidence suggesting inflammation can increase stem cell proliferation, regulating the inflammatory properties of cancer stem cells through cytokine networks may also result in effective new therapies. The positive feedback loops generated by interactions with inflammatory cytokines such as interleukin drive cancer stem cell self-renewal [19]. Anti-inflammatory agents have the ability to block signals from the tumour microenvironment, potentially targeting CSCs in the process [19]. Therapeutics using anti-inflammatory agents to control CSC proliferation are relatively new and clinical trials are being conducted to test their benefits.

The recently developed technology, Moonlight, can be used to identify these critical cancer driver genes [25]. Presented in 2020, this technology has identified 3 dual-role genes, genes that are responsible for either oncogenic or suppressive behaviour depending on their subjected conditions [25]. These genes are difficult to identify due to their volatile nature, however, Moonlight has successfully identified BCL2, SOX17, and ANGPTL4 [25]. Moonlight has taken information from key cell pathways to determine these cancer driver genes and hopes to continue using this technology with single-cell -omics data to reveal pathways and cancer driver genes that hide residual tumour cells [25].

With this research comes many caveats. Not every tumour will react the same way to treatment, and thus it is important to continue researching and developing new technologies that expand the scope of cancer treatment. The limited scope of this review only covers a small subsection of cancer stem cells but serves as a reference point to the relationship between the models of tumour heterogeneity and possible areas to target. 
UNDERGRADUATE RESEARCH IN NATURAL AND CLINICAL SCIENCE AND TECHNOLOGY (URNCST) JOURNAL Read more URNCST Journal articles and submit your own today at: https://www.urncst.com

\section{Conclusion}

This review highlights two main CSC therapeutic methods targeting tumor microenvironments and pathways that lead to the proliferation of mutation. The challenge associated with current patient treatment brings the need for personalized treatments, and further research focused on determining how tumour cells of a cancer colony behave in each patient (models for tumour heterogeneity) will provide important information surrounding the prognosis and course of treatment. Subsequently, upon discovery of how each model influences the colony, specific surface markers and dosage requirements can be determined.

\section{List of Abbreviations Used}

ABCG2: ATP-binding cassette super-family G member 2

Akt: Ak strain transforming

ANGPTL4: angiopoietin-like 4

APC: adenomatous polyposis coli

BCL2: B-cell lymphoma 2

Bmi-1: polycomb complex protein

CD133: cluster of differentiation 133

CD34: cluster of differentiation 34

CD44: cluster of differentiation 44

CK19: cytokeratin 19

C- MYC: cancer myelocytomatosis

CpG: cytosine-phosphate-guanine

CSCs: cancer stem cells

CSF2: colony stimulating factor 2

DNA: deoxyribonucleic acid

DNMT: DNA methyltransferase

EGF: epidermal growth factor

EMT: epithelial-mesenchymal transition

FGF: fibroblast growth factor

Gli1: glioma associated oncogene 1

HDAC: histone deacetylases

HIF-1: hypoxia inducible factor 1

HIF-1a: hypoxia inducible factor 1a

HIF-2a: hypoxia inducible factor $2 \mathrm{a}$

IFNGR: interferon gamma receptor 1

IKK $\beta$ : inhibitor of nuclear factor kappa-b kinase subunit

beta

IL6: interleukin 6

IL8: interleukin (IL)-8

Jag1: jagged canonical notch ligand 1

Jag2: jagged canonical notch ligand 2

JAK/STAT: Janus kinase/signal transducer and activator of transcription

KLF5: Kruppel-like factor 5

KRAS: Kirsten rat sarcoma viral oncogene homolog

KRT15: keratin 15

LEF1: lymphoid enhancer binding factor 1

LgR5: leucine-rich repeat-containing g-protein coupled receptor 5

LIN28: lineage modifying gene 28

MAPK: mitogen-activated protein kinase

miR-1: microRNA 1
miRNA: micro ribonucleic acid

mRNA: messenger ribonucleic acid

mTOR: mechanistic target of rapamycin

mTORC2: mechanistic target of rapamycin complex 2

NANOG: Nanog Homeobox

NF1: neurofibromatosis type 1

NK: natural killer

NF-кB: nuclear factor kappa-light-chain-enhancer of

activated $\mathrm{B}$ cells

NLRP3: nucleotide-binding domain (NOD)-like receptor

protein 3

Notch1: notch receptor 1

Notch3: notch receptor 3

NTRK: neurotrophic tyrosine receptor kinase

Oct4: octamer binding transcription factor 4

P53: protein 53

PATCHED1: patched 1

PDK1: 3-phosphoinositide-dependent kinase 1

$\mathrm{pH}$ : power of hydrogen

PI3K: phosphoinositide-3-kinase

PTEN: phosphatase and tensin homolog

RNA: ribonucleic acid

RNS: reactive nitrogen species

ROS: reactive oxygen species

SALL4: Sal-like protein 4

SHH: sonic hedgehog

Smad2: Mothers against decapentaplegic homolog 2

SOX17: SRY-Box transcription factor 17

SOX-2: SRY-Box transcription factor 2

SOX4: SRY-Box transcription factor 4

STAT1: signal transducer and activator of transcription 1

TCF-4: transcription factor 4

TGF- $\beta$ : transforming growth factor-beta

TGF $\beta 1$ : transforming growth factor-beta 1

TP53: tumour protein 53

TSG: tumour suppressor gene

Wnt: wingless-related integration site

\section{Conflicts of Interest}

Both authors declare that there are no conflicts of interest.

\section{Ethics Approval and/or Participant Consent}

The study did not require ethics approval or participant consent. This paper is presented as a literature review, and no data collection involving human or animal participants was required.

\section{Authors' Contributions}

YG: Contributed to the conception and design of the work, the acquisition, analysis, and interpretation of data for the work and drafted the work, revising it critically for important intellectual content. Gave final approval for this version to be published and agreed to be accountable for all aspects of the work in ensuring that questions related to the accuracy or integrity of any part of this work are appropriately investigated and resolved. 
UNDERGRADUATE RESEARCH IN NATURAL AND CLINICAL SCIENCE AND TECHNOLOGY (URNCST) JOURNAL Read more URNCST Journal articles and submit your own today at: https://www.urncst.com

NR: Contributed to the conception and design of the work, the acquisition, analysis, and interpretation of data for the work and drafted the work, revising it critically for important intellectual content. Gave final approval for this version to be published and agreed to be accountable for all aspects of the work in ensuring that questions related to the accuracy or integrity of any part of this work are appropriately investigated and resolved.

\section{Acknowledgements}

We would like to acknowledge Siobhan O'Brien for her help with editing and guidance for this paper.

\section{Funding}

This study was not funded.

\section{References}

[1] Faguet GB. A brief history of cancer: Age-old milestones underlying our current knowledge database. International Journal of Cancer. 2014 Aug 11;136(9):2022-2036. https://doi.org/10.1002/ijc.29134

[2] Kim YJ, Siegler EL, Siriwon N, Wang P. Therapeutic strategies for targeting cancer stem cells. Journal of Cancer Metastasis and Treatment. Journal of Cancer Metastasis and Treatment; 2016;2:233-242. https://doi.org/10.20517/2394-4722.2016.26

[3] Meacham CE, Morrison SJ. Tumour heterogeneity and cancer cell plasticity. Nature. 2013 Sep 18;501(7467): 328-337. http://doi.org/10.1038/nature12624

[4] Yang L, Shi P, Zhao G, Xu J, Peng W, Zhang J et al. Targeting cancer stem cell pathways for cancer therapy. Signal Transduction and Targeted Therapy. 2020 Feb 7;5(8). http://doi.org/10.1038/s41392-0200110-5

[5] Sun H-R, Wang S, Yan S-C, Zhang Y, Nelson PJ, Jia H-L, et al. Therapeutic Strategies Targeting Cancer Stem Cells and Their Microenvironment. Frontiers in Oncology. 2019 Oct 24;9(1104). http://doi.org/10.3389/fonc.2019.01104

[6] Niekerk Gvan, Davids LM, Hattingh SM, Engelbrecht AM. Cancer stem cells: A product of clonal evolution? International Journal of Cancer. 2016 Sep 27;140(5):993-999. http://doi.org/10.1002/ijc.30448

[7] Marjanovic N, Weinberg R, Chaffer C. Cell Plasticity and Heterogeneity in Cancer. Clinical Chemistry. 2013 Jan 1;59(1):168-179. http://doi.org/10.1373/clinchem.2012.184655

[8] Laconi E. The evolving concept of tumor microenvironments. BioEssays. 2007 Jul 9;29(8):738744. http://doi.org/10.1002/bies.20606

[9] Bindra RS, Glazer PM. Genetic instability and the tumor microenvironment: Towards the concept of microenvironment-induced mutagenesis. Mutation Research/Fundamental and Molecular Mechanisms of Mutagenesis. 2005 Jan 6;569(1-2):75-85. http://doi.org/10.1016/j.mrfmmm.2004.03.013
[10] Pennacchietti S, Michieli P, Galluzzo M, Mazzone M, Giordano S, et al. 2003. Hypoxia promotes invasive growth by transcriptional activation of the met protooncogene. Cancer Cell. 2003 Apr 1;3(4):347-361. http://doi.org/10.1016/s1535-6108(03)00085-0

[11] Salk J, Fox E, Loeb L. Mutational Heterogeneity in Human Cancers: Origin and Consequences. Annual Review of Pathology: Mechanisms of Disease. 2010 Feb;5(1):51-75. http://doi.org/10.1146/annurev-pathol$\underline{121808-102113}$

[12] Matsui W. Cancer stem cell signaling pathways. Medicine. 2016 Sep; 95(1):8-19. http://doi.org/10.1097/MD.0000000000004765

[13] Beachy PA, Karhadkar SS, Berman DM. Tissue repair and stem cell renewal in carcinogenesis. Nature. 2004 Nov 17;432(7015):324-31. http://doi.org/10.1038/nature03100

[14] Ilango S, Paital B, Jayachandran P, Padma PR, Nirmaladevi R. Epigenetic Alterations in Cancer. Frontiers in Bioscience. 2020 Mar 1;25:1058-1109. https://doi.org/10.2741/4847

[15] Toh T, Lim J, Chow E. Epigenetics in cancer stem cells. Molecular Cancer. 2017 Feb 1;16(29). http://doi.org/10.1186/s12943-017-0596-9

[16] Ohnishi S, Ma N, Thanan R, Pinlaor S, Hammam O, Murata M, Kawanishi S. DNA damage in inflammation-related carcinogenesis and cancer stem cells. Oxidative Medicine and Cellular Longevity. 2013 Dec 5; 2013. http://doi.org/10.1155/2013/387014

[17] Bao B, Ahmad A, Li Y, Azmi AS, Ali S, Banerjee S, Kong D, Sarkar FH. Targeting CSCs within the tumor microenvironment for cancer therapy: A potential role of mesenchymal stem cells. Expert opinion on Therapeutic Targets. 2012 Aug 9;16(10):1041-1054. http://doi.org/10.1517/14728222.2012.714774

[18] Casey SC, Vaccari M, Al-Mulla F, Al-Temaimi R, Amedei A, Barcellos-Hoff MH, Brown DG, Chapellier M, Christopher J, Curran CS, Forte S. The effect of environmental chemicals on the tumor microenvironment. Carcinogenesis. 2015 Jun 19;36(Suppl_1):S160-S183. http://doi.org/10.1093/carcin/bgv035

[19] Ames BN. Identifying environmental chemicals causing mutations and cancer. Science. 1979 May 11;204(4393):587-593. http://doi.org/10.1126/science.373122

[20] Korkaya H, Liu S, Wicha MS. Regulation of cancer stem cells by cytokine networks: Attacking cancer's inflammatory roots. Clinical Cancer Research. 2011 Jun 17;17(19):6125-6129. https://doi.org/10.1158/1078-0432.ccr-10-2743

[21] Cabarcas SM, Mathews LA, Farrar WL. The cancer stem cell niche-there goes the neighborhood? International Journal of Cancer. 2011 Nov 15;129(10):2315-27. http://doi.org/10.1002/ijc.26312 
UNDERGRADUATE RESEARCH IN NATURAL AND CLINICAL SCIENCE AND TECHNOLOGY (URNCST) JOURNAL Read more URNCST Journal articles and submit your own today at: https://www.urncst.com

[22] Hou J, Wang L, Long H, Wu H, Wu Q, Zhong T, Chen $\mathrm{X}$, Zhou C, Guo T, Wang T. Hypoxia preconditioning promotes cardiac stem cell survival and cardiogenic differentiation in vitro involving activation of the HIF$1 \alpha /$ apelin/APJ axis. Stem cell Research \& Therapy. 2017 Sep 29;8(215). http://doi.org/10.1186/s13287017-0673-4

[23] Hill RP, Marie-Egyptienne DT, Hedley DW. Cancer stem cells, hypoxia and metastasis. InSeminars in radiation oncology 2009 Apr 1 (Vol. 19, No. 2, pp. 106-111). WB Saunders.
[24]Ziello JE, Jovin IS, Huang Y. Hypoxia-Inducible Factor (HIF)-1 regulatory pathway and its potential for therapeutic intervention in malignancy and ischemia. The Yale Journal of Biology and Medicine. 2007 Jun;80(2):51. https://www.ncbi.nlm.nih.gov/pmc/articl es/PMC2140184/

[25] Colaprico A, Olsen C, Bailey M, Odom G, Terkelsen $\mathrm{T}$, Silva $\mathrm{T}$ et al. Interpreting pathways to discover cancer driver genes with Moonlight. Nature Communications. 2020 Jan 3;11(69). http://doi.org/10.1038/s41467-019-13803-0

\section{Article Information}

Managing Editor: Jeremy Y. Ng

Peer Reviewers: Amy Yeung, Daniel Tarade

Article Dates: Received Apr 02 21; Accepted May 19 21; Published Jun 1421

\section{Citation}

Please cite this article as follows:

Rambharack NN, Guo YR. Proposed models of functional heterogeneity in cancer and the effects of microenvironmental factors on cancer stem cells: A literature review. URNCST Journal. 2021 Jun 14: 5(6).

https://urncst.com/index.php/urncst/article/view/256

DOI Link: https://doi.org/10.26685/urncst.256

\section{Copyright}

(C) Neetu N. Rambharack, Ying R. Guo. (2021). Published first in the Undergraduate Research in Natural and Clinical Science and Technology (URNCST) Journal. This is an open access article distributed under the terms of the Creative Commons Attribution License (https://creativecommons.org/licenses/by/4.0/), which permits unrestricted use, distribution, and reproduction in any medium, provided the original work, first published in the Undergraduate Research in Natural and Clinical Science and Technology (URNCST) Journal, is properly cited. The complete bibliographic information, a link to the original publication on http://www.urncst.com, as well as this copyright and license information must be included.
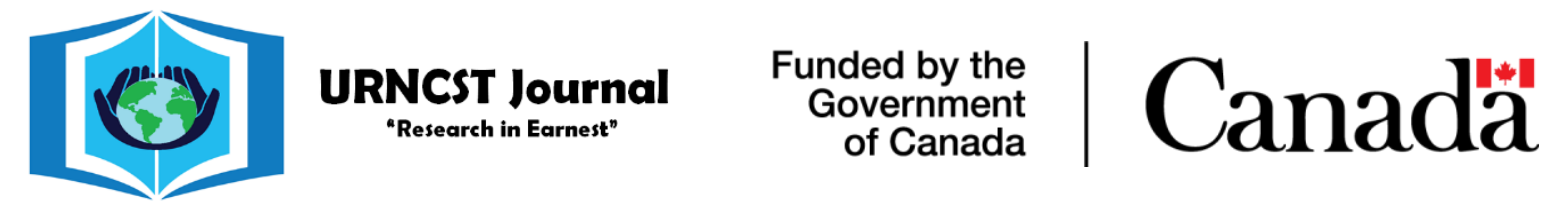

Do you research in earnest? Submit your next undergraduate research article to the URNCST Journal!

| Open Access | Peer-Reviewed | Rapid Turnaround Time | International |

| Broad and Multidisciplinary | Indexed | Innovative | Social Media Promoted |

Pre-submission inquiries? Send us an email at info@ urncst.com | Facebook, Twitter and LinkedIn: @URNCST

Submit YOUR manuscript today at https://www.urnest.com! 